\title{
APOLOGÍA DEL PUEBLO CHILENO: CONTEXTO E IMPLICACIONES DEL DISCURSO DE JUAN IGNACIO MOLINA ${ }^{1}$
}

\author{
Catalina FUENZALIDA CARO ${ }^{2}$ \\ Pontificia Universidad Católica de Chile - Universidad de León, España
}

\begin{abstract}
RESUMEN: Enmarcada en la "Disputa del Nuevo Mundo", la reivindicación del reino de Chile desplegada por el Abate Juan Ignacio Molina en los ensayos sobre su historia natural y civil, basa sus fundamentos en un concepto de cultura que fusiona corrientes intelectuales antiguas y modernas en un pensamiento híbrido, fruto de la cultura jesuita americana en el exilio. Pero a fines del s. XVIII, periodo de definiciones radicales en la historia de pensamiento, esta escuela se mostrará inviable. La incomprensión de este contexto ha instaurado imágenes arquetípicas que dificultan la integración del tema en la historiografía americana y chilena en particular.
\end{abstract}

PALABRAS CLAVE: arquetipo, hibridismo, reivindicación.

ABSTRACT: Enclosed in the "Dispute of the New World", the claim of The Reign of Chile presented by Juan Ignacio Molina abbé, in his essays about natural and civil history, establishes its principles on a concept of culture which joins old and present intellectual currents, putting them together in a hybridist thought, by consequence of the American- Jesuit culture living in exile. However, by the end of XVIII century, a period of clear-cut definitions in the history of thought, this school will show itself as not viable. The incomprehensibility of this context has renewed images as an archetype which makes difficult the integration of the subject in the American historiography and Chilean historiography in particular.

KEYWORDS: archetype, hybridism, claim.

\section{LOS ESTUDIOS MOLINIANOS: HACIA UN PROGRESIVO ANÁLISIS DEL DISCURSO}

El clásico lenguaje que caracteriza a la obra dedicada al naturalista chileno Juan

\footnotetext{
${ }^{1}$ Recibido el 9 de septiembre de 2009 y aceptado para su publicación el 22 de septiembre de 2009.

${ }^{2}$ Agradezco a Gloria Caro Castañeda su valiosa colaboración en la edición de este artículo.
} 
Ignacio Molina es el del homenaje y la reivindicación ${ }^{3}$. En 1856, Benjamín Vicuña Mackenna, en gran parte responsable de la construcción y difusión de la imagen arquetípica de Molina para la opinión pública chilena ${ }^{4}$, instauraba con el discurso a propósito de la fundación de su monumento ${ }^{5}$ la base de una tradición historiográfica de larga vigencia en torno al Abate, también cultivada por el historiador Diego Barros Arana ${ }^{6}$, la que nos muestra a Molina como un sabio excepcional dentro de un panorama colonial viciado. Molina, sabio sin tiempo, sería un claro antecedente de la nación ilustrada que proyecta la aristocracia chilena de mediados del siglo XIX.

Desde entonces, una serie de mitos basados en esta concepción decimonónica se popularizaron a través diversas investigaciones hasta la década de 1970. El año 1946, Januario Espinosa con su obra El Abate Molina: uno de los precursores de Darwin $^{7}$, resucitó el interés historiográfico por la obra moliniana. La continuidad del antiguo discurso es patente en el prólogo redactado por Francisco Antonio Encina: Molina "sabio europeo"8 de talla internacional, estaría al nivel de las más

${ }^{3}$ Aunque el tono patriótico impreso en el discurso promoliniano se gestó en Chile, el afán reivindicativo de los estudios molinianos encuentra sus raíces en Italia. El mismo año 1856, Antonio SANTÁGATA pronunciaba ante la Academia de las Ciencias de Bolonia un Elojio de Juan Ignacio Molina (Imprenta del Ferrocarril, Santiago 1856, p. 1.) donde señalaba: "He aquí aquel de quien voy a ocuparme, y he aquí también el mismo joh dolor! Que todavía no ha sido dignamente celebrado". (Todas las citas de este artículo se presentan en formato modernizado).

${ }^{4}$ Benjamín Vicuña Mackenna. Páginas de mi diario durante tres años de viaje, 1853-18541855. Universidad de Chile, 1936, Capítulo XXV. En el año 1855, Vicuña Mackenna compró una serie de documentos inéditos relativos a Juan Ignacio Molina, además se entrevistó con Von Humboldt, quién le comunicó su favorable opinión sobre el Abate. Resulta interesante, en este mismo capítulo, una carta de Diego Barros Arana, quien le informa sobre algunas indagaciones de datos biográficos de Molina en base a documentos de su juventud conservados en el Archivo Nacional de Santiago. Ésta investigación fue sin duda un importante impulso al conocimiento de su trayectoria.

5 La realización de este monumento estuvo a cargo del escultor Auguste François y su inauguración definitiva tuvo efecto el 16 de Septiembre de 1860, permaneciendo en Santiago hasta 1927, año en que se trasladó definitivamente a Talca.

${ }^{6}$ Benjamín Vicuña Mackenna. Páginas de mi diario durante tres años de viaje..., op. cit. En referencia a la carta enviada a Vicuña Mackenna y la posterior difusión de estos datos por Barros Arana en la obra Historia general de Chile, Tomo VII. Ver también: Benjamín VicuÑa MACKENNA. Rasgos biográficos del Abate Juan Ignacio Molina, primer historiador de Chile. Santiago, Imprenta del Ferrocarril, 1856.

${ }^{7}$ Januario EspinosA. El Abate Molina: Uno de los precursores de Darwin. Zig-Zag, Santiago de Chile, 1946.

${ }^{8}$ El uso de este término, tradicional en el contexto del iluminismo dieciochesco, no respondía al origen del literato sino a su filiación al mundo ilustrado entendido como el ámbito de la vanguardia y la universalidad del pensamiento por excelencia. 
altas autoridades del saber universal de su época. Esta idea fue rescatada en la misma línea por Rodolfo Jaramillo en 1963 en el artículo "El Abate Juan Ignacio Molina, primer evolucionista y precursor de Teihard de Chardin", , consagrando así un enfoque que pasaría a ser clásico y que marcaría con fuerza un discurso que proclama al Abate como el primer científico de corte moderno de la nación. Dos años más tarde, el mismo autor da un paso más a propósito del hallazgo de un diario manuscrito ${ }^{10}$ de Juan Ignacio Molina, exponiendo una verdadera arenga por su reconocimiento como precursor del movimiento emancipatorio chileno. Relacionando el año 1810, cuando la carrera de Molina estaba en pleno apogeo, con la formación de la primera junta nacional de gobierno en Chile, declaró: "Que Molina sea, por ello, doble símbolo de una futura independencia nacional: de la independencia científica y de la independencia del pensamiento chileno." ${ }^{11} \mathrm{La}$ extensión de su supuesto vanguardismo científico a la esfera política es evidente, lo que se explica en buena parte en que el conocimiento de las virtudes intelectuales de Juan Ignacio Molina fue durante mucho tiempo patrimonio casi exclusivo del medio científico chileno ${ }^{12}$. Proviniendo de un medio rara vez cuestionado, no es de extrañar que exacerbaciones como ésta hayan logrado un nivel tan alto de aceptación, desligándose de una adecuada crítica historiográfica. Walter Hanisch marcó un giro en esta interpretación, publicando desde 1973 hasta 1999 de manera casi ininterrumpida, numerosas obras que combinaron las distintas miradas y conocimientos acumulados respecto a Molina desde hace ya más de un siglo, proponiendo nuevas áreas de investigación para el redescubrimiento de su legado. Empezando con Un ataque dieciochesco a Juan Ignacio Molina ${ }^{13}$ en homenaje al

9 Rodolfo JARAmiLlo. «El Abate Juan Ignacio Molina, primer evolucionista y precursor de Teilhard de Chardin». Revista Mapocho, $\mathrm{N}^{\circ}$ 2, 1963.

${ }^{10}$ Rodolfo JARAmILLO. «Descubrimiento de un diario manuscrito inédito del Abate Don Juan Ignacio Molina en el que se registran: sucesos de política internacional europea, principalmente guerras napoleónicas entre 1809 y 1815». Memoria de incorporación del profesor Rodolfo Jaramillo Barriga como Miembro de Número de la Academia Chilena de Ciencias Naturales. Revista Universitaria, $\mathrm{N}^{\circ} 28-29,1965-1966$, pp.7-14.

${ }^{11}$ Ibid., p. 8.

12 Algunos incluso se atrevieron a dar continuidad a sus postulados, profundizando sus propuestas. Como ejemplo podemos citar el trabajo del jesuita Guillermo EBEL. «El quintral de Molina». Revista Universitaria, $\mathrm{N}^{\circ}$ 15, 1930, pp. 96-106. Más recientemente, el profesor Hugo GUNCKEL LÜER editó por lo menos hasta el año 2001 una revista de botánica en honor a Molina titulada Moliniana. Al parecer esta publicación no tuvo continuidad más allá de ese año, en Miguel ROJAS-MIX. El fin del milenio y el sentido de la historia Lacunza y Molina. LOM Ediciones, Santiago de Chile, 2001, p. 78.

${ }^{13}$ Walter HANISCH. Un ataque dieciochesco a Juan Ignacio Molina. Nihil Mihi, Santiago de Chile 1976. 
profesor Guillermo Feliú Cruz, la obra de Hanisch destaca por su aporte en el avance hacia el reconocimiento de Molina como sabio de su tiempo, inserto en una extensa y compleja red intelectual. Especial mención merece la publicación de un Epistolario de Juan Ignacio Molina ${ }^{14}$ en conjunto con Charles E. Ronan.

Pero no sólo es Walter Hanisch quien irrumpe en 1973 con sus aportes al conocimiento de la trayectoria del Abate, también lo hace Julio Jiménez Berguecio con El Abate Molina, humanista clásico y sabio cristiano $^{15}$, una obra que según el autor se inspira en el espíritu riguroso de su protagonista, exponiendo un impresionante tratado de discusión bibliográfica. Pero aunque los anexos de su obra incluyan algunos escritos poéticos de Juan Ignacio Molina en su juventud, la obra en su conjunto no ayuda a comprender mayormente el ambiente ni el desarrollo de la carrera de Molina en el exilio boloñés. A pesar de los avances y de lo interesante que resulta la evolución de la imagen historiográfica del Abate, continuamos hasta el momento en el plano de la biografía y el anecdotario, sin indagar decididamente en el ambiente dieciochesco que lo rodeó.

A pesar de estos antecedentes, recientemente han surgido interesantes estudios que se dirigen en este sentido. El año 1993, Patricio Oyaneder Jara publicó el artículo "Aspectos Modernos del pensamiento de Juan Ignacio Molina"16, donde lejos de reparar en detalles de su biografía, despliega un satisfactorio análisis de su obra identificando en ella una clara "filiación moderna, o mejor dicho, ilustrada (...)"17. Luego, en 1998, Augusto Salinas aporta al conocimiento del medio intelectual de Molina un estupendo artículo titulado "El abate Molina y la ciencia de su época" 18 , el que a nuestro parecer es uno de los acercamientos más serios y acabados al tema, identificando una clara filiación de la obra de Juan Ignacio Molina con una escuela de pensamiento más bien tradicional vinculada principalmente al creacionismo. Ya el año 2001 encontramos la obra de Miguel Rojas-Mix: El fin del Milenio y el sentido de la historia, Manuel Lacunza y Juan

${ }^{14}$ Walter HANISCH, Charles Ronan. Epistolario de Juan Ignacio Molina. Editorial Universitaria, Santiago de Chile, 1979. En esta compilación puede comprobarse la intensa sinergia existente entre jesuitas exiliados y su amplia red de comunicaciones con el mundo laico.

15 Julio Jiménez BergueCio. El abate Molina, humanista clásico y sabio cristiano. Anales de la Facultad de Teología (Universidad Católica de Chile), Vol. 24, Cuaderno 2, 1973.

16 Patricio OYANEDER. «Aspectos modernos en el pensamiento de Juan Ignacio Molina». Philosophica $\mathrm{N}^{\circ} 16,1994$, pp. 71-86.

${ }^{17}$ Ibid., p.85.

${ }^{18}$ Augusto SALINAS. «El abate Molina y la ciencia de su época». Revista Universum. Universidad de Talca, $\mathrm{N}^{\circ} 13,1998$. 
Ignacio Molina ${ }^{19}$ donde el autor se atreve a reivindicar su figura más allá de su método, calificando a Molina como un verdadero "filósofo de la historia". Por último, un estudio reciente de José Stuardo ${ }^{20}$ nos confirma las auspiciosas proyecciones del enfoque ampliado con que se analiza actualmente el legado moliniano en el marco de un renovado impulso al estudio de la historia intelectual de Chile.

La segunda parte de este artículo se enmarca dentro la actual inquietud por replantear las bases teóricas de análisis de la figura y obra de Juan Ignacio Molina. Teniendo en cuenta el sello neoescolástico de su formación y el carácter enciclopédico de su obra, propio del cuadro de replanteamiento de la intelectualidad europea de fines del siglo XVIII, pretendemos mostrar cómo esta fusión que transita entre el método tradicional y el discurso moderno adoptado principalmente en el exilio boloñés entre 1767 y 1829, generó un tipo de pensamiento que reflejó fielmente los problemas epistemológicos del cambio de paradigma que dio luz a la ciencia contemporánea. Este ejercicio resulta fundamental para aclarar de algún modo la extensa serie de lugares comunes que rodean hasta hoy el estudio de la trayectoria de este literato ${ }^{21}$.

${ }^{19}$ Miguel Rojas- MiX. El fin del milenio..., op. cit.

20 José R. StUARDO. «Trascendencia del primer Saggio sulla storia naturale del Chili de J.I. Molina, su traducción, el Compendio anónimo y el Bicentenario». Atenea (Concepción) $\mathrm{N}^{\circ}$. 495, Concepción 2007. Resulta interesante el análisis de la introducción respecto a la supuesta autoría de Molina del Compendio anónimo de 1776 (Compendio della storia geografica, naturale, e civili del regno del Chile. Bologna: Nella stamperia di S. Tommaso D'Aquino, 1776), la que correspondería en realidad al jesuita chileno Felipe Gómez de Vidaurre. Gran parte de la confusión se debería a la traducción al castellano de la obra de Molina originalmente titulada Saggio sulla storia naturale del Chili como Compendio de la historia geográfica, natural y civil del reyno de Chile. Primera parte, que abraza la historia geográfica y natural por el traductor Domingo Joseph de Arguellada y Mendoza el año 1788.

21 Miguel BATLlori. La cultura hispano-italiana de los jesuitas expulsos. Españoles, hispanoamericanos, filipinos, 1767-1814. Editorial Gredos, Madrid, 1966, p. 55. El término "literatos" con que se autodefinían desde químicos y botánicos hasta autores de cartas y versos en la Italia dieciochesca tiene, según el autor, la capacidad de describir al tipo del intelectual enciclopedista típico de este ambiente. 


\section{EL DISCURSO DE JUAN IGNACIO MOLINA A TRAVÉS DE LAS OBRAS ENSAYO SOBRE LA HISTORIA NATURAL ${ }^{22}$ Y ENSAYO SOBRE LA HISTORIA CIVIL DE CHILE ${ }^{23}$}

\subsection{Sistematización y difusión}

En el prólogo del Ensayo sobre la Historia Natural de Chile de 1782, Molina señala claramente los límites de su trabajo:

"El mismo título de la obra anuncia lo que ella es en sí: conviene á saber, un compendio, una breve memoria de algunos de los seres y de las cosas naturales que contiene el Reyno de Chile, y por lo mismo tendrán á bien las personas inteligentes no exigir ni esperar de ella lo que solo conviene a una historia natural (...)"24.

Esto no afectó su objetivo enciclopédico de compilación crítica del material referido a la historia natural y civil de Chile. Molina es ante todo un sistematizador ${ }^{25}$, José Antonio González lo identifica incluso como el "Primer bibliógrafo propiamente chileno" ${ }^{26}$. La finalidad de esta labor fue la publicidad sin fines directamente comerciales (recordemos que Molina no servía a ningún estado en particular) del escaso y disperso conocimiento existente acerca de un país casi desconocido, pero pleno de condiciones favorables para el desarrollo de una vida civil estrechamente ligada a su potencial industrial:

"[Respecto a la edición de 1782] Los caracteres distintivos de los objetos fueron presentados de un modo demasiado conciso, como para cumplir los

22 Juan Ignacio Molina. Compendio de la historia geográfica, natural y civil del Reyno de Chile, primera parte, que abraza la historia geográfica y natural. Traducción de Domingo Joseph de Arguellada y Mendoza. Madrid, 1788. Versión original publicada en 1782.

23 Juan Ignacio Molina. Compendio de la Historia Civil del Reyno de Chile. Traducción de Nicolás de la Cruz y Bahamonde. Impr. de Sancha, Madrid, 1795 Al final de la obra se incluye un "Catálogo de los escritores de las cosas de Chile". Versión original publicada en 1787.

${ }^{24}$ Juan Ignacio Molina. Compendio de la historia geográfica, natural y civil del Reyno de Chile, primera parte, que abraza la historia geográfica y natural..., op. cit., p. XIV.

25 Juan Ignacio Molina. Compendio de la Historia Civil del Reyno de Chile..., op. cit. Al final de la obra se incluye un "Catálogo de los escritores de las cosas de Chile".

${ }^{26}$ José Antonio GonZÁlez. La Compañía de Jesús y la ciencia ilustrada: Juan Ignacio Molina y la Historia natural y civil de Chile. Universidad Católica del Norte, Antofagasta, 1993, p. 50. Con esta afirmación, González consolida una visión de la labor del Abate ya anunciada por Hugo Gunckel, quien refiriéndose a Molina apuntó “(...) debemos considerarlo el precursor de la sistemática de la Historia Natural Chilena.”, en Hugo GuNCKEL. «Plantas chilenas descritas como nuevas por Juan Ignacio Molina y sus concordancias con la nomenclatura botánica actual». Noticiero Mensual del Museo Nacional de Historia Natural, Año XVII, N 197, 1972, pp. 3-11. 
anhelos de los naturalistas doctos, pero que resultó suficiente para satisfacer la curiosidad de aquellas personas que sólo buscan darse una idea de la calidad y producciones de los países lejanos. Este fue el único fin que me propuse al componer ese opúsculo., ${ }^{27}$

Vale la pena dar un vistazo a la gran cantidad de autores que tuvieron en Molina, ya sea a un referente, o un blanco para sus críticas ${ }^{28}$. A pesar de la diversidad de opiniones respecto a la calidad de la obra moliniana, no cabe duda de que ésta representó, para muchos exploradores y futuros científicos modernos, un primer acercamiento a los asuntos tocantes a la historia política y natural de Chile.

La obra de Molina se muestra dinámica dentro de su propia lógica. La reedición de su Ensayo sobre la Historia Natural de Chile en 1810, no es sólo producto de la recuperación de sus antiguos apuntes extraviados, sino de la preocupación propia de un ilustrado por mantener vigentes sus aportes al conocimiento. Citando nuevamente el prólogo de 1810, apreciamos con claridad la preocupación por reforzar la validez de su obra: "[En referencia el Ensayo sobre la Historia Natural... de 1782] Después de varias reflexiones, me decidí a rehacerla totalmente, insertando en los lugares respectivos aquellas observaciones que, por los motivos ya indicados, había dejado de lado"29.

El primer objetivo de difusión que caracteriza sobre todo al Ensayo sobre la Historia Natural..., encuentra continuidad y se revela plenamente en el discurso reivindicativo desplegado en el Ensayo sobre la Historia Civil de Chile. Es allí donde Molina plasma toda la complejidad del pensamiento jesuita en el exilio y su particular interpretación de la realidad de su colonia natal, Chile, la que inexorablemente ha de incorporarse al curso providencial de la modernidad.

${ }^{27}$ Juan Ignacio Molina. Compendio de la historia geográfica, natural y civil del Reyno de Chile, primera parte, que abraza la historia geográfica y natural..., op. cit., p. 3.

28 Walter HANISCH. Juan Ignacio Molina sabio de su tiempo. Ediciones Nihil Mihi. Santiago, 1976, pp. 127-177. Entre lo autores que lo citan podemos encontrar a Gian Rinaldo Carli, Antonio José Cavanilles, Francisco Javier Clavigero, Lamarck, Alcedo, Charles d'Orbigny y Kant por nombrar sólo algunos. Por otro lado, entre sus más acérrimos detractores, encontramos a Brogniart, Cuvier, Candolle y Felipe Salvador Gilij. Las expediciones de José Celestino Mutis y Ruiz y Pavón llevaban el Ensayo sobre Historia Natural de Chile entre sus libros de consulta.

29 Juan Ignacio Molina. Compendio de la historia geográfica, natural y civil del Reyno de Chile, primera parte, que abraza la historia geográfica y natural..., op. cit., p. 4. 


\subsection{Apología del pueblo chileno}

\subsubsection{Bajo las paradojas de la ilustración y la cultura jesuita dieciochesca}

Aunque en términos comparativos el Ensayo sobre la Historia Civil de Chile de 1787 no resulte tan novedoso como el Ensayo sobre la Historia Natural..., donde se describió por primera vez con el método taxonómico de Linneo una importante muestra de la flora y fauna de la costa chilena ${ }^{30}$, esta obra resulta interesante a efectos de identificar con claridad la forma y los objetivos del discurso del autor.

Es así como en una lectura atenta podemos distinguir diversas corrientes intelectuales de época mezcladas con el enfoque tradicional de la neoescolástica ${ }^{31}$. Este hibridismo no resultaría apreciable en su verdadera magnitud sin tener en cuenta un episodio fundamental de la cultura jesuita en el exilio, el de la "Disputa del Nuevo Mundo"32, momento de esplendor pero también de enviciamiento de un tipo de pensamiento donde la tensión entre la vieja escolástica y el pensamiento moderno no llegaron a armonizarse lo suficiente como para instaurar una escuela basada en la unión de estos principios. Signo de los tiempos, la acelerada desaparición de patrones cada vez más irreconciliables con los nuevos

30 José R. STUARDO. «Trascendencia del primer Saggio sulla storia naturale del Chili...», op. cit. Epílogo.

31 Mario GóNGORA. «Estudios sobre el Galicanismo y la Ilustración católica en América Española». Revista Chilena de Historia y Geografia, $\mathrm{N}^{\circ} 125,1957$, pp. 125- 133. El autor destaca el ambiente ecléctico y crítico de los exjesuitas en el exilio como un momento de transición entre la escolástica y la ilustración: "Los jesuitas modernos pueden agruparse fácilmente dentro de las nuevas tendencias, antes o después de la expulsión" (p. 147). Esto comienza con el abandono forzado del llamado "dictado" característico de la educación escolástica debido a carencia de apuntes bibliográficos para terminar la formación de los diecinueve hermanos estudiantes exiliados en Italia (Januario EsPINOSA. El abate Molina: Uno de los precursores de Darwin..., op. cit., pp. 97-98). Walter HANISCH. «El ambiente chileno y europeo en la formación de Juan Ignacio Molina». Universum, $\mathrm{N}^{\circ} 1$, Universidad de Talca, 1986, p. 9: En Chile antes de 1767, ya se practicaban de hecho algunas reformas a la Ratio Studiorum propias de la influencia ejercida por el movimiento ilustrado católico: "En el tiempo en que realizaba sus estudios de filosofía Juan Ignacio Molina, ya los profesores prefieren publicar sus clases como cursos de filosofía, divididos en materias, y no como comentarios a las obras del Estagirita. En este tiempo se separan las ciencias de la naturaleza de la filosofía (...)", la aplicación oficial de estas reformas por el gobierno borbónico llegó luego de la expulsión, ver: Mario GÓNGORA. «Aspectos de la ilustración católica en el pensamiento y la vida eclesiástica chilena: (1770-1814)». Historia, N ${ }^{\circ} 8,1969$, también Alamiro Ávila MARTEL. «La Universidad y los estudios superiores en Chile en la época de Carlos III». En Estudios sobre la época de Carlos III en el Reino de Chile, Santiago, Ediciones de la Universidad de Chile, 1988, pp. 183184.

32 Antonello GerBI. La disputa del nuevo mundo: historia de una polémica: 1750-1900. Traducción de Antonio Alatorre. Segunda Edición. Fondo de Cultura Económica, México, 1982. 
planteamientos filosóficos daría a luz al revolucionario siglo XIX. La querella entre los antiguos y los modernos simboliza un cambio de paradigma fundamental ${ }^{33}$ del que los jesuitas exiliados fueron vivo testimonio:

“(...) tenían en el rostro el estigma de los practicantes de la nueva ciencia, pero las manos eran de curas obsequiosos con el orden antiguo. Por eso se aconsejaban entre sí defender "las orientaciones de la buena física" con "un poco de hipocresía ante los peripatéticos y escolásticos..." Eran, por decirlo de algún modo, "modernos" que no alcanzaban a ser "ilustrados", como lo pedía el nuevo siglo." 34

En el Ensayo sobre la Historia Civil..., Molina describe desde las diversas teorías acerca del arribo de la población indígena al territorio a la que denomina como "chilena", hasta el estado del reino para finales de la centuria. En sus líneas podemos distinguir tanto los rasgos más nobles de la ilustración como su cara más oscura, aquella que totaliza el concepto de cultura, cuyo origen es privativamente europeo. Es allí donde se ha descubierto la luz verdadera de la razón moderna, punto culminante de la evolución del pensamiento que conducirá al desciframiento de los más profundos secretos de la naturaleza y el espíritu ${ }^{35}$. Esta verdad universal debía de ser difundida a todos aquellos rincones que por diversas circunstancias no habían alcanzado la luz del progreso, principalmente por medio del comercio, llave que abriría la puerta al contacto con naciones más civilizadas, clave para el desarrollo material y civil de los pueblos.

En este caso, el concepto de cultura que podemos distinguir en el discurso de Molina coincide con la apreciación de Maravall respecto a la evolución adelantada de este término en el mundo hispánico ${ }^{36}$. Ésta sería producto del proceso de desarrollo histórico de cada nación, el que determina el estadio de desarrollo de su

33 Para ampliar este tema ver: Chris HEESAKKERS. «El clasicismo francés y su proyección en Europa. La Querelle de los antiguos y los modernos». En Antiquae lectiones: el legado clásico desde la Antigüedad hasta la Revolución Francesa / Juan Signes Codoñer... [et al.]. Cátedra, Madrid, 2005.

34 Salvador Gallardo CABrera. «La disputa por la diferencia». En Ciencias, No 48. UnAm, México, 1997, p. 10.

35 José Antonio MARAVALL. «La palabra civilización y su sentido en el siglo XVIII». En Estudios de la historia del pensamiento español: siglo XVIII. Mondadori, Madrid, 1991.

${ }^{36}$ Ibid., p. 218. Respecto a la evolución de la voz "cultura” Maravall señala: “(...) tiene sentido que en España esa evolución se adelantara porque en ella se contemplaba de siglos atrás, en el recinto mismo de la península, y desde fines de siglo XV, en medios exóticos -Canarias, América- la coexistencia de grupos étnicos que no sólo diferían por alguna costumbre, algunos mitos, algún aspecto particular de su mentalidad y sus modos de vida, sino que las diferencias se apreciaban en el conjunto de cuanto les atañía. Hacía falta ya, desde muy pronto, una palabra que designara globalmente esos conjuntos diferenciales y fue la palabra "cultura" la que vino a usarse a tal objeto." 
vida social. Esta noción se mezcla con la "teoría de los cuatro estadios" ${ }^{37}$ de la que se vale para clasificar a los chilenos como agricultores ${ }^{38}$, esta tesis profundamente ligada a una idea de progreso cuyo fin último es la libertad, sería la base de la cara tutelar de la ilustración cuyo arraigo puede relacionarse con la visión de Aristóteles acerca de la esclavitud en La Politica ${ }^{39}$. Si el hombre moderno vive en el cuarto estadio de la evolución, el del comercio, su influencia y guía resulta provechosa, e incluso necesaria para aquellos pueblos que viven en un nivel más atrasado.

No es difícil reconocer en Molina una postura que, sin otra posibilidad de elección en los términos planteados por el iluminismo dieciochesco, es indiscutiblemente europeocentrista. El objetivo de su obra, luego de publicitar un país desconocido, es reivindicar la imagen que las "naciones cultas" tienen del pueblo chileno, subestimado injustamente por la intelectualidad europea: "El Doctor Robertson, pues, generalizó demasiado sus ideas cuando los colocó en el rol de cazadores, profesión que ellos quizá no abrazaron, sino en los primeros tiempos de su establecimiento en Chile." ${ }^{40}$

Su principal arma en esta lucha fue la asimilación de "lo chileno" al origen, es decir, a Europa y sus instituciones. En este sentido seguimos la opinión de Jorge Cañízares Esguerra cuando respecto a Molina señala: “(...) este jesuita criollo

${ }^{37}$ María Fuencisla AlCón Yustas. El pensamiento político y jurídico de Adam Smith. La idea de orden en el ámbito humano. Prólogo de Dalmacio Negro Pavón. UPCo, Madrid, 1994, p. 143: “(...) la "teoría de los cuatro estadios" fue formulada en Europa por dos autores casi simultáneamente, alrededor de 1750, sin que existiese entre ellos contacto alguno: Smith y el francés Turgot (...). No obstante, la construcción de Smith fue más completa que la de Turgot, especialmente en lo que se refiere al cuarto estadio, la era del comercio, que en Turgot está sólo en germen, mientras que Smith la desarrolló ampliamente tanto en los aspectos económicos, como en los sociales y políticos." La autora señala además, en base a las conclusiones de Ronald MeEK (Smith, Marx y después. Diez ensayos sobre el pensamiento económico; cap. II, p. 30 y Los orígenes de la Ciencia Social, cap I, p. 35.) que "(...) a lo largo de toda la historia del pensamiento pueden encontrarse pensadores que sostuvieron que el desarrollo del hombre se produjo en etapas sucesivas, pero hasta los trabajos de Turgot y Smith, especialmente de éste último, no se construyeron exposiciones doctrinales serias", p. 144.

${ }^{38}$ Juan Ignacio Molina. Compendio de la Historia Civil del Reyno de Chile..., op. cit., pp. 12-13.

39 Aristóteles. La Política. Carlos García Gual y Aurelio Pérez García (Eds.) Editora Nacional, Madrid, 1981. Libro I, cap. V "La esclavitud II: Justificación natural”, pp. 53-55. En la "teoría de los cuatro estadios", cada una supera intelectualmente a la otra, abandonando progresivamente la fuerza física para resolver diversas situaciones, desde el tipo de actividad productiva hasta el liderazgo político. En Aristóteles la justificación natural de la esclavitud radica tanto en la superioridad de la razón sobre la fortaleza física como en la conveniencia del dominio de la una sobre la otra.

${ }^{40}$ Juan Ignacio Molina. Compendio de la Historia Civil del Reyno de Chile..., op. cit., pp. 12-13. 
estaba interesado en ofrecer a la intelectualidad europea una descripción de América que encajara en los moldes de la historia europea desde los tiempos clásicos hasta la Edad Moderna" ${ }^{41}$. A pesar de esto, existe un matiz considerable que enriquece la perspectiva de la obra de Juan Ignacio Molina, en este sentido es preciso recordar que entre los móviles que le llevaron a concebir el Ensayo sobre la Historia Natural..., destacó su afición desde temprana edad a la observación y a la investigación ${ }^{42}$, mucho antes de encontrarse en las circunstancias que lo consagraron como naturalista en la Europa dieciochesca.

Lo anterior confirma el origen difuso de la posición intelectual de los jesuitas que abrazaron la causa de la reivindicación de sus respectivas patrias en el exilio. Molina escribió no sólo para la comprensión de Chile en términos europeos, sino también porque valoró intrínsecamente su potencial físico y humano para llegar a ser una nación plenamente civilizada. Si el discurso de Francisco Javier Clavijero se guió por una mezcla de "determinaciones ideales e impulsos naturales" ${ }^{43}$, en el caso de Molina aquellas determinaciones se encuentran plenamente regladas bajo los principios de la racionalidad y el criticismo, pues cada uno de los fundamentos expuestos obedece a la lógica del pensamiento ilustrado. Esta importante diferencia metodológica podría explicar la ausencia de registros que avalen la comunicación entre Molina y Clavijero, o lo que es más sorprendente, la de Molina con Manuel

41 Jorge CAÑízARES ESGUERRA. «Controversias entre europeos y criollos a fines del 700». En Fénix de España: modernidad y cultura propia en la España del siglo XVIII (1737-1766). Actas del congreso internacional celebrado en Madrid, noviembre de 2004: homenaje a Antonio Mestre Sanchos. Pablo Fernández Albaladejo (ed.). Madrid: Marcial Pons, 2006, p. 331.

${ }^{42}$ Miguel BATLlori. La cultura hispano-italiana..., op. cit., p. 85. El interés por las ciencias de la naturaleza en ningún caso es patrimonio exclusivo de la ciencia ilustrada, al respecto Batllori señala: "La afición a las ciencias positivas- tan clara en Pinazó, en Ludeña, en Ponz- no puede decirse que sea en ellos un rasgo típico de la ilustración, pues venía ya de la antigua tradición jesuita de Clavio, de Kircher, de Grimaldi, etc.”. Es claro que para completar esta observación es necesaria una investigación acabada acerca de los autores que Molina estudió durante su formación en Chile. Tenemos alguna noción de sus influencias gracias a Walter HANISCH en su Historia de la Compañia de Jesús en Chile (Editorial Francisco de Aguirre, Buenos Aires, 1974, pp. 106-108), donde aporta modestas noticias al respecto señalando sólo la cantidad de obras con que contaban las bibliotecas del Colegio Máximo de San Miguel y de Concepción sin señalar su clasificación.

43 Salvador Gallardo CABRERA. «La disputa por la diferencia...», op. cit., p.14. Mientras el jesuita mexicano Francisco Javier ClaviJero en su Historia Antigua de México buscaba la filiación entre lo europeo y lo americano a través en una explicación basada en la autoridad de la Biblia, identificando el origen de la humanidad y del mundo natural en el triunfo de Noé luego del diluvio universal, Molina la encontró en un principio abstracto, el de la cultura, concepto asimilable al de desarrollo social que se hace presente en todas los naciones del mundo en distintos grados. 
Lacunza, chileno que trascendió por su renovación del milenarismo ${ }^{44}$ en pleno siglo de las luces.

El intelectual que aparece ante nosotros, sin llamarse plenamente moderno, está profundamente imbuido en la lógica de su tiempo. Ambos ensayos sobre la Historia Geográfica, Natural y Civil del Reyno de Chile resultan un conjunto armónico que en suma constituyen una importante muestra del tipo de pensamiento en un principio marginal y luego universal de los jesuitas americanos.

A pesar del mal diagnóstico de Molina respecto al estado de un Chile tardocolonial alejado del desarrollo de las bellas artes y la mecánica, la esperanza en un pronto despegue del país está presente en varios pasajes de su obra ya que "La importante revolución, que el Soberano va felizmente promoviendo en todo género de útiles conocimientos, se ha propagado hasta aquellas partes." ${ }^{45}$ Esta observación no resta créditos a su dura crítica a la forma en que la Corona conducía el comercio del reino, haciendo hincapié en la nula acuñación de monedas de cobre $^{46}$. Con esto, más que comprobar cualquier filiación política de Molina, confirmamos la directriz ilustrada de sus planteamientos:

"Cuando la ilustración europea criticaba tan despiadadamente la colonización española de América no lo hacía por promover la autonomía individual y colectiva de los americanos -menos aún de los originarios, los amerindios-, sino la perspectiva colonial de la sociedad comercial" ${ }^{47}$.

Si bien este enfoque coincide con la postura de Molina, en el caso de los jesuitas americanos esta crítica se suaviza debido a su aún estrecha adhesión a la "Madre Patria". Es más, sin identificarse todavía con el gentilicio de sus respectivas patrias, reservan esta denominación a los indígenas del territorio autodenominándose siempre como criollos.

En algunos casos incluso, entre los que destacaron el ya citado Francisco Javier Clavijero y el quiteño Juan de Velasco, se intentó identificar antiguas constituciones prehispánicas con el objeto de destacar el libre acuerdo de estas naciones con la monarquía española más "No se vinculó este afán a un proyecto

${ }^{44}$ Manuel Lacunza. Venida del Mesías en gloria y majestad. Cádiz: Felipe Tolosa, 1812.

45 Juan Ignacio Molina. Compendio de la Historia Civil del Reyno de Chile..., op. cit., p. 318.

${ }^{46}$ Ibid., pp. 326-329.

47 José M. PORTILLO VALDÉS. «Americanos españoles. Historiografía, identidad y patriotismo en el Atlántico Hispano». Fénix de España: modernidad y cultura propia en la España del siglo XVIII..., op. cit., p. 327. 
para hacerlas valer como señal de una posición como partes principales de la monarquía." 48

La obra de estos jesuitas mezcla una serie de elementos cuya complejidad es difícilmente traducible a términos actuales. Por una parte la crítica ilustrada al sistema colonial y por otro, la justificación de esta empresa en los mismos principios pues el contacto con naciones más civilizadas conduciría a la evolución social de los pueblos más atrasados. La clave para entender la consistencia de esta posición radica nuevamente en la naturaleza del término razón, en la época, una noción netamente europea que no permitió la apertura a la compresión de sus propias deficiencias que por lo demás, no se consideraron como tales. Los movimientos independentistas del siglo XIX no avanzaron mayormente en este sentido pues la base argumentativa de la emancipación siguió siendo la misma en esencia, así "El patriotismo criollo no hizo uso de la historia política prehispánica para subrayar una continuidad constitucional resultante de un proceso de incorporación y no de simple conquista"49. Relegadas al pasado, las glorias políticas de los antiguos habitantes de América sirven sólo para demostrar la normalidad antropológica de una estirpe que anhela sanear su pasado.

A continuación veremos cómo en su reivindicación del pueblo chileno, Molina se valió no sólo de argumentos renovados como la vieja fórmula de la asimilación al centro, es decir a Europa, sino también el primer determinismo moderno que aún no adquiría la importancia y el desarrollo que alcanzó en la siguiente centuria.

\subsubsection{La lengua de los chilenos}

Una parte importante de su propuesta se basó en el análisis de la lengua chilena $^{50}$, siguiendo una estrategia que recuerda la metodología de Adam Smith en

48 Jorge CAÑízARES ESGUERRA. «Controversias entre europeos y criollos a fines del 700...», op. cit., p. 332.

${ }^{49}$ Ibid., p. 333.

${ }^{50}$ En referencia a la lengua de los araucanos (mapuches), el llamado "mapudungú". Si bien el término "chileno" es usado para toda la población nativa del territorio, en este caso es empleada para designar a los pueblos de la región de Arauco que para Molina serían los mejores exponentes de la cultura ancestral del reino. Este es el motivo por el cual muchas veces emplea indistintamente los términos "pueblo chileno" y "araucanos". Juan Ignacio Molina. Compendio de la Historia Civil del Reyno de Chile..., op. cit., p. VIII. "Se encuentran muchas gramáticas impresas y manuscritas de este idioma, pero yo me he servido especialmente de la del Señor Fabrés, impresa en Lima, capital del Perú, el año 1765, la cual por el método y por la claridad, es digna de particular recomendación." 
su ensayo "Consideraciones concernientes a la primera formación del lenguaje" 51 . En el capítulo inicial del Ensayo sobre la Historia Civil..., titulado "Origen, fisonomía y lengua de los chilenos", Molina destaca la complejidad de esta lengua en cuyo alfabeto "no hay alguna letra gutural, ni vocal aspirada, lo que es muy de admirar en una nación inculta." ${ }^{, 52}$. Este argumento es fundamental para rescatar el valor de un pueblo que hasta el momento se considera salvaje:

"La perfección de las lenguas sigue constantemente la de la civilización; ni se puede comprender cómo una nación siempre salvaje, que jamás ha sido limada ni por las sabias leyes, ni por el comercio, ni por las artes, pueda hablar un idioma culto, expresivo y abundante. ${ }^{, 53}$

Si la cultura de un pueblo se entiende como la unidad fundamental de su desarrollo material y espiritual ${ }^{54}$, esta fórmula no permitiría dimensionar aisladamente una esfera como el lenguaje, cimiento del mundo abstracto, las artes y la vida en común. De ahí la insistencia de Molina en este punto y el interesante análisis de la similitud de esta "habla" con las lenguas griega y latina. Es importante destacar que el estudio de estas coincidencias no obedeció a ningún tipo de teoría antropológica seudocientífica, sino más bien a la intención de hacer comprensible al "mundo culto" un lenguaje casi completamente desconocido en Europa y que había surgido al otro lado de la ecúmene de modo original:

“(...) lo que puede parecer singular es, que se encuentren en esta lengua vocablos, que parecen de origen griego, o latino del mismo significado, los cuales para satisfacer la curiosidad de los etimologistas apuntaré en el compendio de la misma habla, que se encontrará al fin de este volumen, aun que yo no vea más que una mera accidentalidad." 55

51 Añadido a la tercera edición de The Theory of Moral Sentiments; Edited by D.D RÁPALE and A.L. MACFIE; Clarendon Press; Oxford, 1976. Según este ensayo, el estado de la lengua de una nación sería una importante medida de su progreso. Aunque la idea de progreso resultara popular en la segunda mitad del siglo XVIII, la aplicación sistemática de la "teoría de los cuatro estadios" planteada por SмiтH en Lecciones sobre jurisprudencia (Curso 1762-3. Introducción de Manuel Escamilla Castillo. Comares, Granada, 1995) y la metodología del análisis lingüístico, parecen evidenciar la influencia de este autor en Molina.

52 Juan Ignacio Molina. Compendio de la Historia Civil del Reyno de Chile..., op. cit., p. 333.

53 Ibid., p. 5.

${ }^{54}$ María Fuencisla AlCón Yustas. El pensamiento político y jurídico de Adam Smith..., op. cit. p. 142. "[Respecto a la "teoría de los cuatro estadios"] Cada una de estas etapas representa un avance en relación al anterior y, aunque están determinadas por el modo de subsistencia, no sólo afectan a la economía, sino que deciden la prosperidad en todos los ámbitos de la vida del hombre.”, pp. 142-143.

55 Juan Ignacio MolinA. Compendio de la Historia Civil del Reyno de Chile..., op. cit, p.8. 
Fragmento del cuadro de similitudes entre las lenguas chilena, griega, italiana y castellana. Juan Ignacio MolinA. Compendio de la Historia Civil del Reyno de Chile..., op. cit., p. 334

\section{VOCES CHILENAS GRIEGAS.}
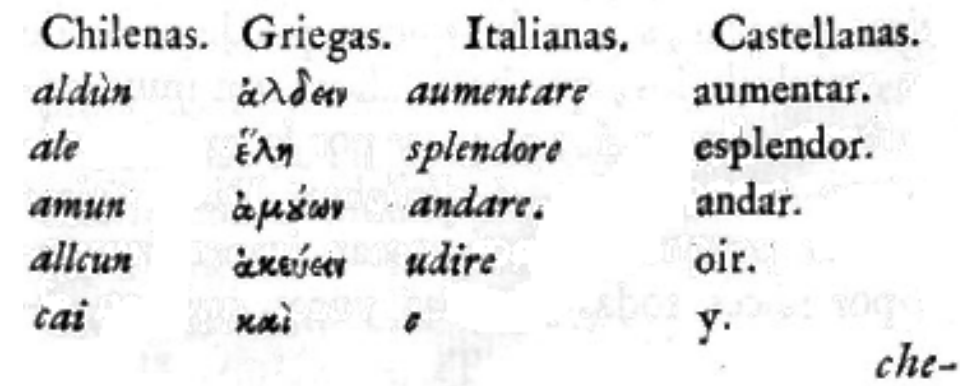

Como se puede apreciar, la forma de asimilar el valor de esta lengua va más allá de una simple traducción ${ }^{56}$. El paralelo establecido entre las cuatro lenguas sirve a la estrategia del autor, quien pretende dar cuenta de una idea universal de cultura, una esencia común de lo humano que se desarrolla en grados dependiendo de las circunstancias históricas de cada pueblo. Es por esto que se recalca constantemente la originalidad de esta coincidencia:

"No es muy fundada la opinión sostenida por algunos, que los chilenos hayan tomado las susodichas palabras de la lengua española, así porque ellas no están por la mayor parte en uso en esta lengua, como porque se encuentran registradas en los primeros vocabularios hechos de su idioma." ${ }^{57}$

También ejercicios del lenguaje como la poesía y la retórica han encontrado su lugar en Arauco. Respecto al célebre coyagtucán, arenga parlamentaria donde se expresa la lengua araucana en toda su plenitud, Molina señala:

56 Juan María GutiérRez. Historia y Crítica. Prólogo de Clara Rey de Guido. Fundación Biblioteca Ayacucho, 2004, p. 73. Respecto a las gramáticas escritas por misioneros y algunos estudios de cronistas sobre Chile, señala: "Esas gramáticas, aun aquellas recientemente impresas con las pretensión de mejorarlas, son pesadas y confusas. Adolecen del gran defecto de estar basadas sobre la índole de las lenguas griega y latina, complicando con los apartados nebricences el sencillo mecanismo de esta lengua verdaderamente primitiva cuya formación está sujeta a leyes que le son peculiares." Molina sin embargo, usa este recurso para confirmar la originalidad de la lengua chilena.

57 Juan Ignacio Molina. Compendio de la Historia Civil..., op. cit., p., 336. 
"No obstante, estas oraciones contienen todas las partes esenciales que requiere la retórica artificiosa; lo que no debe causar maravilla, porque aquellos habitantes han aprendido el uso en la misma naturaleza, la cual condujo a los griegos a reducir en arte la elocuencia.",58

Si en el desarrollo de las artes del discurso los araucanos siguieron espontáneamente el modelo de las grandes civilizaciones de la antigüedad, también lo hicieron con modelos de gobierno y prácticas sociales bien conocidas en el "Viejo Mundo", lo que constituye una segunda batería de argumentos para reivindicar al pueblo chileno.

\subsubsection{Gobierno y usos sociales}

Claramente enmarcado en la "Disputa del Nuevo Mundo", el discurso reivindicativo de Molina no declara culpables de la mala comprensión de Chile sólo a aquellos modernos que como Buffon y De Pauw ${ }^{59}$ echaron a relucir las más creativas teorías respecto la inferioridad de América, sino también a la perspectiva informativa de las primeras noticias acerca del reino:

"Los primeros europeos que llegaron a aquellos países, pusieron sus miras en otros objetos menos interesantes, cuidando poco o nada de aquellas cosas que suelen llamar la atención de un genio observador al presentarse a una nación desconocida." 60

Esta verdadera negligencia a ojos de Molina, agravaría la mala comprensión de un pueblo que como el chileno, ha sido subestimado por literatos que han generalizado las observaciones de viajeros que describieron preferentemente a los pueblos selváticos de América del Sur ${ }^{61}$.

En nombre de la ciencia y haciendo justicia a su patria desde uno de los epicentros más importantes de la cultura dieciochesca como lo fue Bolonia, Molina expone una serie de hipótesis ${ }^{62}$ y pruebas que revelan el real estado de desarrollo del pueblo chileno.

58 Ibid., p. 102.

59 Son varios los pasajes del Ensayo de la Historia Geográfica, Natural y Civil del Reyno de Chile que podríamos citar al respecto, sin embargo resulta interesante destacar el capítulo XX del Ensayo sobre la Historia Natural... donde Molina comprueba la inoperancia de las "leyes graduales" de Pauw.

60 Juan Ignacio Molina. Compendio de la Historia Civil del Reyno de Chile..., op. cit., p. 27.

${ }^{61}$ Salvador GALlardo CABRERA. «La disputa por la diferencia...», op. cit., p. 14.

62 Juan Ignacio Molina. Compendio de la Historia Civil del Reyno de Chile..., op. cit., p. 27. Luego de un misceláneo repaso de la cultura araucana Molina apunta: “(...) en su lengua se 
Sobre una compleja división del territorio en cuatro Butalmapus, lo que supone "ya un cierto grado de refinamiento en la política administración", Molina reconoce en el gobierno de los araucanos una aristocracia plutocrática. ${ }^{63}$ Esta se dividiría en tres órdenes de representantes: los Toquis, tetrarcas que preceden los Butalmapus, los Apo- Ulmenes, gobernadores de las provincias o aillaregues que son cinco por cada Butalmapu bajo el mando del Toqui y por último los Ulmenes, jefes locales de los nueve regues existentes por provincia: "He aquí los Duques, los Condes, y los Marqueses de la aristocracia militar del septentrión, establecidos desde tiempo inmemorial, bajo diferentes nombres, en un ángulo de la América Meridional. ${ } 64$

A pesar de que Molina cataloga a los araucanos como bárbaros a la llegada de los conquistadores, es decir, "en aquel estado medio entre lo salvaje y lo civil",65, la conformación tradicional de la aristocracia en este nivel cultural estaría determinada por las glorias bélicas, lo que no coincidiría con el método empleado por los araucanos quienes basan su autoridad en la riqueza. Como podemos apreciar, a pesar de las numerosas similitudes encontradas con la cultura europea, la evolución del pueblo araucano ha seguido una lógica particular que en todo momento es destacada por el autor.

También a través de otras pistas más aisladas pero igualmente novedosas, Molina intenta completar el bosquejo verdadero del pueblo araucano transmitiendo su admiración al observar varias características que sorprenderían al "mundo culto". Así llama la atención sobre su desarrollo en áreas como la música, el arte militar y la medicina, donde los araucanos han demostrado conocimientos que ya son ancestrales en el occidente ${ }^{66}$.

Es entonces que los araucanos y por extensión los chilenos, lejos de presentarse como un conjunto de tribus relegadas a las más profundas tinieblas del salvajismo, de costumbres selváticas como la mutilación o el alargamiento de sus miembros como lo planteaba Buffon en su Tratado del Hombre, son una nación que aunque bárbara al arribo de la colonización, guarda todo el potencial de desarrollo de los

encuentran indicios de otras varias artes, que no nos atrevemos a exponer, porque no tenemos bastantes guías idóneas, para dirigirnos en una materia importante y equívoca al mismo tiempo."

${ }^{63}$ Ibid., p. 20. La voz "ulmen" con la que se denomina a los jefes locales, tiene el significado de "hombre rico".

${ }^{64}$ Ibid., pp. 61-62.

${ }^{65}$ Ibid., p. 26.

${ }^{66}$ Ibid., p. 108. En referencia a las “(...) sangrías, las ayudas, las calas, los vomitivos, los catárticos y los diaforéticos." 
antiguos pueblos que en el siglo XVIII se presentan como naciones plenamente civilizadas, incluso con la ventaja de hallarse lejos de muchos de los vicios que invaden a la Europa Moderna.

Haciéndose eco de un lugar común en su época, Molina también defiende al pueblo chileno en términos algo rusonianos. El estilo de vida del araucano, aunque bárbaro y escasamente apegado a las normas civiles, tiene mucho que aportar a un mundo culto que en el trance a la vida civilizada ha perdido el recuerdo de aquellos valores originales que apelan a la esencia misma del hombre. El araucano, de carácter indómito (característica constantemente destacada por Molina), no es capaz de asimilar los intentos absolutistas de sus jefes, quienes ejercen sobre el pueblo un tipo de poder más bien simbólico basado en el respeto a los primeros entre los iguales, a aquellos que dirigen al pueblo en caso de conflictos bélicos aguardando por el bienestar general de la comunidad:

"Los señores, engolosinados con el dominio, quisieran ampliar su autoridad, y gobernar como absolutos dueños. Pero el pueblo, que no está aún en estado de sobrellevar el despotismo, huye de sus pretensiones, y los obliga a contenerse dentro de los límites prescriptos por la costumbre." ${ }^{.67}$

Pero la aristocracia araucana comparte con sus pares en Europa los defectos universales de este tipo de sistema "Este gobierno, bajo la apariencia del sistema feudal, conserva también casi todos sus defectos. Los toquis no tienen más que la sombra de la soberanía." Los congresos deliberatorios del Gran Consejo de los Araucanos, donde se reúnen representantes de los tres ordenes "(...) se hacen de ordinario en algún espacioso prado, donde no se delibera sobre los negocios públicos, sino entre los placeres de la mesa." ${ }^{\circ 8}$

Cabe señalar de inmediato que Molina estuvo lejos de idealizar la cultura araucana y menos aún de dar por agotado el debate en torno al tema ${ }^{69}$, lo que constituye uno de sus méritos más notables como literato. Su esfuerzo por encontrar la hebra de la esquiva objetividad se deja notar en cada juicio, en cada apreciación, como un testigo que quiere mimetizarse con la realidad, casi un médico que diagnostica el estado de una cultura teniendo en cuenta los pros y los contras de cada situación según las circunstancias que la determinan. Un buen ejemplo de este estilo es su exposición acerca de las leyes de los araucanos.

${ }^{67}$ Ibid., p. 64.

${ }^{68}$ Ibid., p. 62.

${ }^{69}$ Ibid., p. VIII. El autor señala que ha añadido un catálogo de los escritores de las cosas de Chile pues podría ser útil "(...) a aquellos que quieran darnos una historia completa." 
Éstas están contenidas principalmente en el Admapu "que quiere decir, las costumbres del país" ${ }^{, 70}$, sin embargo esta especie de código consuetudinario asimilable a una constitución no contempla la reglamentación de la vida civil, la cual no consta de un corpus específico lo que permite que reine por lo general la ley del más fuerte. La justicia tomada por las propias manos es resuelta en correrías entre grupos enemigos llamadas malocas, que aunque a veces prolongadas y extremadamente violentas, se mantienen dentro de ciertas normas de convivencia fundamentales: "El pueblo, a pesar de su innata fiereza, pocas veces permite el uso de las ramas en las riñas particulares, las cuales se deciden a puñadas, o a palos."71 A partir de esta observación, Molina deja caer una dura crítica al sistema penal occidental:

"La justicia se hace tumultuariamente, y sin alguna de aquellas previas formalidades, en la mayor parte inútiles, que se observan en los países cultos. El reo encontrado culpable de delito capital, es luego destinado a muerte, al uso militar, sin haberlo hecho antes podrirse en las prisiones, las cuales no están en uso en los dicasterios araucanos., ${ }^{, 72}$

Este tipo de observación, propia de la autocrítica de un "mundo culto" que mantiene la nostalgia hacia un pasado altamente teorizado, tiene la ventaja de reconocer el valor de las culturas primitivas no para asimilarlas en términos textuales, sino para seguir progresando en términos atemporales dentro de un panorama intelectual considerado la etapa final de la evolución estructural del pensamiento.

Pero entre las mayores virtudes que demuestran el potencial del pueblo chileno y de Sudamérica en general, está la sensatez practicada en los intercambios comerciales y su capacidad para asimilar las normas básicas del comercio justo y la propiedad privada, consideradas las principales vías de civilización de un pueblo:

"El derecho de privativa propiedad, era plenamente establecido entre los chilenos. Cada uno era dueño absoluto del campo que cultivaba, y de los productos de su industria, los cuales podían transmitir a sus hijos por sucesión hereditaria. De este principio fundamental comenzaron a brotar las primeras artes, que pedían las necesidades de la natural conformidad, no menos que aquellas de la constitución política." ${ }^{73}$

\footnotetext{
${ }^{70}$ Ibid.

${ }^{71}$ Ibid., p. 66.

72 Ibid., p. 65.

${ }^{73}$ Ibid., p. 20.
} 
Esta idea, una de las grandes triunfadoras después de las grandes revoluciones del siglo XVIII, estaba ya profundamente arraigada en Molina. El gérmen del progreso estaba presente entre los araucanos y las reformas de Carlos III $^{74}$ cifraban grandes esperanzas en el desarrollo de un reino que aunque marginal, tenía todas las cualidades para entrar en el concierto de las naciones civilizadas. Si las excelentes condiciones del país no se avenían con el estado de su vida civil y material, esta inercia se debía al aislamiento y a la escasa población del país, que no permitía el surgimiento de un mercado adecuado para el despegue del comercio y la industria: "La falta de ocupaciones hace parecer estas gentes desidiosas, pero yo, que hablo por experiencia, podría asegurar lo contrario (...)"75 .

Para completar su apología, Molina acude como buen sabio de su época a ciertas persistencias deterministas ya tradicionales del mundo europeo que en el siglo XIX se renovarán y fortalecerán de mano del cientificismo. Así los chilenos, además de encontrase a la llegada de los españoles en un estado en que "crecía de grado en grado la esfera de sus ideas. ${ }^{, 76}$, contaban con características que los acercaban al fenotipo de las naciones más cultas: "Aunque su encarnadura sea de un color oscuro inclinado al rojo, como el de los otros americanos, este oscuro todavía es de una tinta más clara, y fácilmente se cambia al blanco.,"77

No es sólo su aspecto, sino también la gallardía de su carácter el que los pone tácitamente por sobre el resto de los americanos. Luego de enumerar varias de las glorias militares españolas y portuguesas en América y las Indias Orientales, donde se triunfó con extrema facilidad sobre los pueblos aborígenes, Molina apunta: "Pero a pesar de la fuerza y el arte, los araucanos permanecen siempre en sus terrenos, lo que hace conocer el valor y constancia de este pueblo.,"78

Juan Ignacio Molina, hombre de su tiempo, nos brinda la posibilidad de distinguir de modo especialmente explícito las confluencias de distintas épocas que sustentan a todo discurso.

\section{CONCLUSIONES}

Comprender el pensamiento de Juan Ignacio Molina no resulta una tarea sencilla teniendo en cuenta los cambios que vive el mundo europeo de la segunda

\footnotetext{
${ }^{74}$ Ibid., p. 318.

${ }^{75}$ Ibid. Nota p. 330.

${ }^{76}$ Ibid., p. 26.

${ }^{77}$ Ibid., p. 4.

${ }^{78}$ Ibid., p. 304.
} 
mitad del siglo XVIII en combinación con una intelectualidad jesuita que en el exilio mantiene una lógica y estilo propios a pesar de las influencias del mundo laico y que para el momento de la expulsión se encontraba replanteando las bases mismas de su metodología ${ }^{79}$. El estudio de los jesuitas americanos se inserta en este panorama, por lo que resulta necesario imbuirnos en un contexto que trasciende al puro localismo para comprender la esencia de este pensamiento. El vacío en torno al tema se ha plagado de lugares comunes que durante décadas se han enquistado en los trabajos referidos a la obra de los jesuitas en el exilio.

En el caso de Chile, desde la década de los '90, ha surgido un nuevo enfoque de la trayectoria del Abate Juan Ignacio Molina que avanza en el entendimiento de su vida y obra a través de su entorno. Pero a pesar de esta ampliación de la perspectiva, estos estudios, en su mayoría, no acaban de eludir del todo aquella tendencia tradicional que busca clasificar a Molina por medio de epítetos que señalan ya sea su supuesto vanguardismo o su arcaísmo más rotundo, de "Humanista clásico" constantemente entre orillas opuestas. Aunque en la fundamentación de los autores estas opiniones no carecen de cierta base, los constantes bautizos de Molina no permiten alcanzar el grado de abstracción suficiente para extender estos análisis a un panorama latinoamericano.

Dos de los grandes argumentos en los que se basa la defensa del vanguardismo de Molina son el enciclopedismo y el interés por la Historia Natural transversales a toda su obra. Estos rasgos, ciertamente ilustrados, también son características propias del jesuitismo que se cultivaban profusamente antes de la expulsión a mediados del siglo XVIII y que se encontraban en proceso de institucionalización en las reformas de la Ratio Studiorum ${ }^{82}$.

Pero sin duda, el gran problema historiográfico que no ha sido suficientemente asimilado en los estudios molinianos, es el del enviciamiento del pensamiento jesuita de fines del siglo XVIII, momento de definiciones capitales en la historia del pensamiento que exigía la adhesión absoluta a los postulados de la razón. Sin asumir del todo los principios de la modernidad, los jesuitas americanos dieron lugar a lo que hoy entenderíamos como un pensamiento híbrido que se valía del

\footnotetext{
${ }^{79}$ Véase p. 11 , nota 30.

${ }^{80}$ Julio JiMÉnez BERGUECIO. El Abate Molina, humanista clásico y sabio cristiano..., op. cit.

${ }^{81}$ Januario EsPINOSA. El Abate Molina: Uno de los precursores de Darwin..., op. cit.

${ }^{82}$ Walter HANISCH. «El ambiente chileno y europeo...», op. cit., p. 9.
} 
discurso moderno, pero que en su esencia aplicaba métodos y conceptos propios de la tradición escolástica.

La obra de Juan Ignacio Molina fluctúa entre una neoescolástica enciclopédica y un prerromanticismo ilustrado, que se reflejan tanto en su sistematización crítica del conocimiento sobre Chile y su respectiva difusión, como en su profunda preocupación por reivindicar la imagen de un país que para finales del s. XVIII aun no se insertaba en el contexto de la modernidad. Molina intentó revertir en cierta medida esta situación catalogando con el método taxonómico de Linneo una considerable muestra de la flora y fauna chilenas. Es este el principal distintivo de su obra respecto a sus antecesores y en especial de su más cercano, Felipe Gómez de Vidaurre.

La revisión de la evolución historiográfica de Juan Ignacio Molina nos confirma que la figura del Abate está todavía inserta en una pugna entre tradición y modernidad que se supone superada en el mundo contemporáneo, lo que desafía nuestras consideraciones acerca del curso tradicional de la historia intelectual latinoamericana. De ahí que la lógica del epíteto se repita con tanta frecuencia y que el análisis del ambiente tardodieciochesco de los jesuitas americanos se considere un tema tácitamente superado.

Aunque el estudio de la vida y obra de Molina lleve más de 150 años, el enfoque propuesto por Benjamín Vicuña Mackenna persistió en los medios especializados hasta hace unos veinte años atrás. Molina, hito de la lucha por la "Civilización" $"$, encontraría continuidad a su labor en los objetivos ilustrados de las autoridades del recientemente consolidado Chile decimonónico.

En la opinión pública, esta es la imagen más viva que se conserva del Abate. Desde mediados del s. XIX y de modo reiterado en la segunda mitad del s. XX, se han realizado múltiples homenajes a propósito de las fechas conmemorativas de su trayectoria. Estas manifestaciones han explotado su supuesto activismo intelectual, lo que ha resultado atractivo para las autoridades políticas en distintos gobiernos y en diversas circunstancias ${ }^{84}$. Molina se ha instaurado como una suerte de comodín

${ }^{83}$ Benjamín Vicuña MACKenNa. La primera piedra del monumento del abate D. Juan Ignacio Molina. Santiago de Chile Imprenta. Chilena, 1856. Esto en el marco del impulso que la Sociedad de Instrucción Primaria quería dar al reconocimiento del pasado intelectual chileno.

84 Municipalidad de Villa Alegre. El regreso del Abate Molina: homenaje en el sesquicentenario de su muerte (1829- 12 de Septiembre de 1979). Linares, 1979. Este homenaje resulta interesante, pues aquí se exhibe una recopilación de distintos documentos que relatan el proceso por el que pasó la comunidad de Villa Alegre para recuperar los restos del abate en 1967, luego de una tensa rivalidad con las autoridades civiles, eclesiásticas e incluso militares de Talca, 
que abre las puertas a aquel Chile docto y excepcional en el panorama latinoamericano, reforzando aquella persistente autoimagen heredada desde mediados del siglo XIX. El impacto de esta apreciación en la historiografía moliniana es notorio en aquel sentido del homenaje que la impregna transversalmente.

Las categorizaciones radicales del papel de Molina, y en general, del conjunto de los jesuitas americanos en el exilio, son construcciones basadas en criterios tradicionales de periodización historiográfica que no admiten las complejidades de un pensamiento americano original gestado principalmente antes de la expulsión y consolidado en la Europa dieciochesca.

Es importante señalar que lejos de entregar dictámenes definitivos, este trabajo ha intentado avanzar en la contextualización de un literato que como Juan Ignacio Molina, estuvo profundamente inmerso en la lógica de su entorno y su tiempo. Esperamos que las conclusiones generadas al respecto ayuden a mejorar la disposición hacia un tema que deja abierto un amplio campo de investigación.

producida por el secuestro de su féretro. El año 1979 se realiza este homenaje que subraya insistentemente la falta de gratitud y el olvido en que quedaron los restos del Abate durante años antes de que llegaran definitivamente al templo parroquial de Villa Alegre en 1969. El Gobernador Provincial de Linares, Coronel Patricio Gualda Tiffaine, señala en el prólogo que el gobierno militar habría tenido como prioridad dentro de su política cultural, enaltecer a las figuras patrióticas que han llevado lejos el nombre del país. Todo esto en el contexto de la inauguración de una plazoleta que llevaría el nombre de Molina y el anuncio de un plan para construir una "Casa de la Cultura" en la comuna.

Otro caso emblemático en Jaime González Colville. Abate Molina. El Mercurio (Santiago) 16 de Mayo de 2002. Sobre el obsequio del presidente Ricardo Lagos del Compendi della Storia Geografica, Naturale y Civile del Reino de Chile al Papa Juan Pablo II en el marco de una visita oficial. 
